\title{
Effect of a minor titanium addition on the superplastic properties of a CoCrFeNiMn high-entropy alloy processed by high-pressure torsion
}

\author{
Hamed Shahmir $^{\mathrm{a}, \mathrm{b}, *}$, Mahmoud Nili-Ahmadabadi ${ }^{\mathrm{a}, \mathrm{c}}$, Ahad Shafiee ${ }^{\mathrm{a}}$, Terence G. Langdon ${ }^{\mathrm{b}}$ \\ ${ }^{a}$ School of Metallurgy and Materials, College of Engineering, \\ University of Tehran, Tehran, Iran \\ ${ }^{b}$ Materials Research Group, Faculty of Engineering and the Environment, \\ University of Southampton, Southampton SO17 1BJ, UK \\ ${ }^{c}$ Center of Excellence for High Performance Materials, School of Metallurgy and Materials, \\ College of Engineering, University of Tehran, Tehran, Iran
}

\begin{abstract}
A CoCrFeNiMn high-entropy alloy (HEA) with an addition of 2 at.\% Ti was processed by high-pressure torsion to produce a grain size of $\sim 30 \mathrm{~nm}$ and then tested in tension at elevated temperatures from 873 to $1073 \mathrm{~K}$ using strain rates from $1.0 \times 10^{-3}$ to $1.0 \times 10^{-1} \mathrm{~s}^{-1}$. The alloy exhibited excellent ductility at these elevated temperatures including superplastic elongations with a maximum elongation of $830 \%$ at a temperature of $973 \mathrm{~K}$. It is shown that the Ti addition contributes to the formation of precipitates and, combined with the sluggish diffusion in the HEA, grain growth is inhibited to provide a reasonable stability in the fine-grained structure at elevated temperatures. By comparison with the conventional CoCrFeNiMn HEA, the results demonstrate that the addition of a minor amount of Ti produces a smaller grain size, a higher volume fraction of precipitates and a significant improvement in the superplastic properties.
\end{abstract}

Keywords: CoCrFeNiMnTi; high-entropy alloy; high-pressure torsion; severe plastic deformation; superplasticity.

*Corresponding author. Tel.: +982182084163

E-mail address: H.Shahmir@ut.ac.ir 


\section{Introduction}

High-entropy alloys (HEAs) have attracted worldwide attention due to their potential beneficial mechanical characteristics such as high strength, good ductility and high thermal stability. HEAs contain five or more elements with each elemental concentration between 5 at. $\%$ and 35 at. $\%$ and an intriguing aspect is that their high configurational entropies favor the formation of simple structures based on solid solution phases over the precipitation of brittle intermetallic compounds [1-3]. Generally, a potential combination of high solid solution strengthening and good ductility may be achieved if the solid solution phase possesses a simple crystal structure, such as an $f c c$ lattice with a large number of slip systems [4]. An example, and one of the best studied such single-phase HEAs, is the equiatomic CoCrFeNiMn alloy which is a single-phase $f c c$ solid solution [5,6]. Experiments show this HEA exhibits very good ductility but its strength is relatively low in the homogenized condition [7]. The strength of the alloy may be increased without significantly sacrificing the ductility by introducing additional strengthening methods such as solid solution or precipitation hardening which require a modification of the chemical composition of the alloy. It is well known in practice that, in addition to the principal elements, HEAs can also contain minor elements with each below 5 at.\% [8].

The high temperature mechanical properties of HEAs were studied earlier [9-12] and some limited results are now available documenting the occurrence of superplasticity in a number of HEAs [13-17]. A recent brief review summarizes the major superplastic results obtained to date [18] and also includes a description of a recent report of superplastic-like flow in a CoCrFeNiMn HEA [19]. It is well established that superplasticity requires a grain size smaller than $\sim 10 \mu \mathrm{m}$ [20] and this may be achieved most readily through the application of severe plastic deformation (SPD) [21,22]. Processing by the SPD technique of high-pressure torsion (HPT), where a disk is subjected to a high applied pressure and concurrent torsional straining [23], is especially effective by comparison with other SPD procedures in producing both 
exceptionally small grain sizes [24,25] and microstructures containing a large fraction of grain boundaries have high angles of misorientation [26]. Thus, processing by HPT appears to be especially attractive for achieving superplastic flow in HEAs. Superplasticity is defined formally as a tensile elongation of at least $400 \%$ [27] and there are reports to date of superplastic behavior with a maximum elongation of $\sim 1240 \%$ when testing at $1273 \mathrm{~K}$ in $\mathrm{AlCoCrCuFeNi}$ processed by multiaxial forging [13-16] and a maximum elongation of $>600 \%$ at $973 \mathrm{~K}$ in $\mathrm{CoCrFeNiMn}$ processed by HPT [17]. Superplastic-like flow with a smaller elongation of $320 \%$ at $1023 \mathrm{~K}$ was also reported in CoCrFeNiMn processed by rolling [19].

Following earlier research on CoCrFeNiMn [17,28], the present research was initiated to provide detailed information on the significance of adding a small amount (2 at.\%) of Ti to the CoCrFeNiMn HEA. Specifically, the investigation examined the influence of the Ti addition on grain refinement by HPT and on the subsequent high temperature mechanical properties in the HPT-processed condition. As will be demonstrated, the addition of Ti is beneficial and the $\mathrm{CoCrFeNiMnTi}_{0.1}$ HEA exhibits enhanced superplastic elongations of up to $>800 \%$ when testing in tension at $973 \mathrm{~K}$.

\section{Experimental material and procedures}

A CoCrFeNiMnTi $0.1\left(\mathrm{Co}_{19.6} \mathrm{Cr}_{19.6} \mathrm{Fe}_{19.6} \mathrm{Ni}_{19.6} \mathrm{Mn}_{19.6} \mathrm{Ti}_{2}\right.$ in at.\%) alloy was prepared using a non-consumable vacuum arc melting technique in a water-cooled copper crucible. After several remeltings to give reasonable homogenization, the ingots were hot forged and then homogenized at $1273 \mathrm{~K}$ for $960 \mathrm{~min}$ to give an initial grain size of $\sim 200 \mu \mathrm{m}$. Polished disks with diameters of $10 \mathrm{~mm}$ and thicknesses of $\sim 0.8 \mathrm{~mm}$ were prepared from the homogenized alloy and then processed by HPT for 5 turns at room temperature (RT) under an applied pressure of $6.0 \mathrm{GPa}$ at $1 \mathrm{rpm}$ using quasi-constrained conditions in which there is a small outflow of material around the periphery of the disk during the torsional straining [29].

Two miniature tensile specimens with gauge dimensions of $1.1 \times 1.0 \times 0.6 \mathrm{~mm}^{3}$ were cut from symmetrical off-centre positions in each disk in order to avoid any deformation 
inhomogeneities in the central regions of the disks [30]. The mechanical properties were measured at temperatures from 873 to $1073 \mathrm{~K}$. The stress-strain curves were recorded at each temperature using initial strain rates from $1.0 \times 10^{-3}$ to $1.0 \times 10^{-1} \mathrm{~s}^{-1}$ at constant displacement rates and with at least two samples tested under each condition to ensure good reproducibility. The stress-strain curves were used to determine the ultimate tensile strength (UTS) and the elongation to failure for each specimen with the elongations checked carefully by measuring the gauge lengths before and after tensile testing. After tensile testing at $973 \mathrm{~K}$ the grip sections were polished to a mirror-like quality and hardness measurements were taken using a Vickers microhardness tester with a load of $500 \mathrm{gf}$ and dwell times of $10 \mathrm{~s}$. In practice, these measurements were recorded after the HPT-processed samples were held at $973 \mathrm{~K}$ for times in the range of 20-140 min. At every indentation point, the local value of the microhardness, Hv, was determined from the average of five separate hardness values.

The phase constituents were determined using X-ray diffraction (XRD) employing $\mathrm{Cu} \mathrm{K} \alpha$ radiation (wavelength $\lambda=0.154 \mathrm{~nm}$ ) at $45 \mathrm{kV}$ and a tube current of $200 \mathrm{~mA}$ with Rigaku SmartLab equipment. These determinations were conducted in the grip sections after tensile testing at $973 \mathrm{~K}$ with initial strain rates of $1.0 \times 10^{-3}$ to $1.0 \times 10^{-1} \mathrm{~s}^{-1}$ and near the edges of the disks for samples before and after HPT processing. XRD measurements were recorded over a $2 \theta$ range from $30^{\circ}$ to $100^{\circ}$ using a scanning step of $0.01^{\circ}$ and a scanning speed of $2^{\circ} \min ^{-1}$. Microstructural characterizations were conducted after tensile testing by examining the gauge lengths and the gripping sections with scanning electron microscopy (SEM). For the SEM observations, samples were ground through 800, 1200 and 4000 grit $\mathrm{SiC}$ papers and then polished using a $40 \mathrm{~nm}$ colloidal silica suspension.

\section{Experimental results}

\subsection{Results from tensile testing after HPT}

Figure 1(a) shows a plot of engineering stress against engineering strain after tensile deformation at $873-1073 \mathrm{~K}$ with an initial intermediate strain rate of $1.0 \times 10^{-2} \mathrm{~s}^{-1}$. The curves 
reveal an initial hardening followed by a peak and then gradual softening before failure. The maximum elongation to failure occurs at $973 \mathrm{~K}$ and there are lower elongations at both lower and higher temperatures. A set of curves is shown in Fig 1(b) after tensile deformation at $973 \mathrm{~K}$ and it is apparent that the total elongation is a maximum at the intermediate strain rate of $1.0 \times$ $10^{-2} \mathrm{~s}^{-1}$. This result demonstrates the occurrence of three distinct regions of flow as in conventional superplastic alloys where the measured elongations decrease at both high and low strain rates [31].

The maximum total elongation recorded in these experiments was $830 \%$ and this confirms the occurrence of true superplasticity. Using the data from Fig. 1(b), the flow stress at $\varepsilon=0.7$ was plotted logarithmically against the initial strain rate in Fig. 1(c) to give a measured value for the strain rate sensitivity, $m$, of $\sim 0.3$ over two orders of magnitude of strain rate.

Examples of superplastic flow are shown by the tensile samples depicted in Fig. 2 where these specimens were tested at $973 \mathrm{~K}$ and show the maximum elongation of $830 \%$ at the intermediate strain rate. All three deformed specimens in Fig. 2 exhibit superplastic elongations and it is clear that the specimens pull out uniformly without any necking as required for true superplasticity [32].

\subsection{Microstructural characteristics before and after HPT processing}

Microstructural evaluations of the HEA before (homogenized) and after HPT processing, and in the grip areas after testing at 973 and $1073 \mathrm{~K}$ with a strain rate of $1.0 \times 10^{-3} \mathrm{~s}^{-1}$, were investigated by $\mathrm{XRD}$ over a $2 \theta$ range from $36^{\circ}$ to $52^{\circ}$ and the results are presented in Fig. 3 . Inspection shows that the HEA is single phase before and after HPT with the $f c c$ phase marked with solid circles in Fig. 3. The occurrence of significant peak broadening of the HEA samples after HPT by reference to the homogenized condition denotes energy storage during the HPT processing. These broadenings were examined for determinations of the grain size in the HPTprocessed sample using the classic Williamson-Hall method $[33,34]$. By this procedure, the grain size after HPT processing was estimated as $\sim 30 \mathrm{~nm}$. In practice, it should be noted that 
the grain size estimated though XRD analysis refers to the crystallite size which is generally considered essentially equivalent to the grain size when the microstructure is refined to the nano-scale [35].

The XRD patterns show also that several peaks appear after tensile testing and these peaks are of two different forms. First, there is a peak marked with a solid inverted triangle at $2 \theta \approx$ $44.2^{\circ}$ and this is related to the formation of a $b c c$ phase which precipitates within the $f c c$-phase matrix. According to the present results, the lattice parameter of this $b c c$ phase is $a \approx 2.88 \AA$ which is in good agreement with the Cr-rich phase reported earlier in the CoCrFeNiMn HEA [36]. Second, there are some peaks of very low intensities marked with open inverted triangles in the sample tested at $973 \mathrm{~K}$. The crystal structure of this phase was identified as tetragonal with lattice parameters of $a \approx 8.8 \AA$ and $c \approx 4.5 \AA$, where this is consistent with the $\sigma$-phase which is a hard Cr-rich phase reported earlier in HEAs [37-39]. Inspections also indicate that, based on the XRD results, the volume fractions of precipitates increase from $\sim 10 \%$ to $\sim 20 \%$ with increasing temperature from 973 to $1073 \mathrm{~K}$.

Figures 4 shows SEM micrographs of the microstructures in the grip section (lower row) and within the gauge section at the head (very close to the fracture tip) (upper row) and near the head (middle row) of the tensile specimens for samples deformed at $973 \mathrm{~K}$ where the strain rates were $(\mathrm{a}-\mathrm{c}) 1.0 \times 10^{-2}$ and $(\mathrm{d}-\mathrm{f}) 1.0 \times 10^{-3} \mathrm{~s}^{-1}$. In Fig. 4 the tensile directions are marked as TD and the specimens correspond to the maximum tensile elongations of $830 \%$ and $650 \%$ for strain rates of $1.0 \times 10^{-2}$ and $1.0 \times 10^{-3} \mathrm{~s}^{-1}$, respectively. It is important to note also that the head area is very close to the fracture point of the specimens. All microstructures in Fig. 4 are equiaxed with average grain sizes of $\sim 400$ and $\sim 600 \mathrm{~nm}$ after testing at $973 \mathrm{~K}$ with strain rates of $1.0 \times 10^{-2}$ and $1.0 \times 10^{-3} \mathrm{~s}^{-1}$, respectively. In addition, there is evidence for the existence of twins after testing as shown by the circles marked in some of the grains. Thus, although these specimens failed at high elongations, there is no evidence for any elongated grains within the 
deformed microstructures and this is consistent with the occurrence of grain boundary sliding (GBS) in conventional superplasticity.

Close inspection of the SEM micrographs in Fig. 4 shows the existence of precipitated phases which are marked with arrows and have diameters of, typically, 300-500 nm. These phases are formed along the grain boundaries which suggests they act as obstacles to grain growth and therefore they are probably beneficial in retaining a reasonably fine grain size at elevated temperatures. Close inspection of Fig. 4(a) reveals also some microcracks in the interfaces between the matrix and the precipitates in the head area.

Microstructural evaluations of the nanostructured HEA in the grip area after testing at $973 \mathrm{~K}$ with strain rates of $1.0 \times 10^{-1}$ to $1.0 \times 10^{-3} \mathrm{~s}^{-1}$ were conducted by XRD and the results are presented in Fig. 5. These patterns are similar to Fig. 3 with several peaks after tensile testing which are of three different forms. First, there are peaks of the $f c c$-phase matrix marked with solid circles. Second, there is a peak marked with a solid inverted triangle related to the formation of the Cr-rich $b c c$ phase which is precipitated within the $f c c$-phase. Third, there are some very low intensity peaks marked with open inverted triangles which again correspond to the $\sigma$-phase. Analysis shows that the volume fractions of the precipitates increase from $~ 9 \%$ to $\sim 12 \%$ with decreasing strain rate from $1.0 \times 10^{-1}$ to $1.0 \times 10^{-3} \mathrm{~s}^{-1}$.

\subsection{Hardness and microstructures after tensile testing}

Figure 6 shows values of the Vickers microhardness in the grip area of tensile samples after HPT but before tensile testing at $0 \mathrm{~min}$ and after testing at $973 \mathrm{~K}$ with strain rates of $1.0 \times 10^{-1}$ to $1.0 \times 10^{-3} \mathrm{~s}^{-1}$ which take from $20-140$ min corresponding to the holding time to reach the testing temperature plus the time of testing: the lower dashed line at $\mathrm{Hv} \approx 140$ represents the initial hardness in the homogenized condition. These results show that the hardness decreases slightly after testing for longer periods of time and this is consistent with the grain size measurements showing the occurrence of some grain growth during testing. 
Figure 7 shows the microstructures in the grip section (labelled Grip), very close to the fracture point in the gauge area (labelled Head) and within the gauge section (labeled Near the Head) of specimens tested at $1073 \mathrm{~K}$ at a strain rate of $1.0 \times 10^{-2} \mathrm{~s}^{-1}$ corresponding to a tensile elongation of $\sim 570 \%$. The observations show microcracks very close to the fracture surface in Fig. 7(a) and (b) with different magnifications and also within the gauge section in Fig. 7(c). Appropriate energy dispersive X-ray spectroscopy (EDS) analyses were recorded for the image shown in Fig. 7(a) where point A corresponds to the matrix and $\mathrm{B}$ corresponds to $\mathrm{Mn}$ and $\mathrm{Cr}$ oxides formed during deformation through in situ oxidation near the crack opening region since $\mathrm{Mn}$ and $\mathrm{Cr}$ are both strong oxide formers. This is consistent with earlier results where CoCrFeNiMn HEA was examined after testing at $1073 \mathrm{~K}[10,17]$.

The microstructural observations reveal a homogeneous equiaxed microstructure both within the gauge section in Fig. 7(c) and in the undeformed grip region in Fig. 7(d) for the sample pulled at $1073 \mathrm{~K}$. This equiaxed structure in Fig. 7(c) confirms the occurrence of GBS and the final grain sizes after deformation were estimated as $\sim 3.0$ and $\sim 1.5 \mu \mathrm{m}$ near the head and in the grip area, respectively. Thus, the results show the occurrence of some limited grain growth during tensile testing and close inspection of the SEM micrographs shows the presence of a precipitated phase, typically $\sim 700-800 \mathrm{~nm}$ in diameter, which is in consistent with the XRD results in Fig. 3. For the SEM micrograph of the sample tested at $1073 \mathrm{~K}$ in Fig. 7(d), results are listed for EDS analyses conducted at the points C and D corresponding to the matrix and a precipitate, respectively. This analysis shows the presence of a $\mathrm{Cr}$-rich phase as reported also in the CoCrFeNiMn HEA [28]. It is important to note that the XRD results in Fig. 3 indicate that the high volume fraction of the $b c c$ phase is stable after testing at $1073 \mathrm{~K}$. It appears also that there is a relatively weak interface between the precipitates and the matrix which promotes the formation of microcracks during tensile testing at $1073 \mathrm{~K}$ and this reduces the elongation to failure at this higher temperature as shown in Fig. 1(a). 


\section{Discussion}

\subsection{Significance of the high temperature tensile results}

The results from this investigation demonstrate that the processing of the CoCrFeNiMnTi $i_{0.1}$ HEA by HPT through 5 turns at RT produces a grain size of $\sim 30 \mathrm{~nm}$ and leads to superplastic elongations when testing at temperatures in the range of 873-1073 K using initial strain rates from $1.0 \times 10^{-3}$ to $1.0 \times 10^{-1} \mathrm{~s}^{-1}$. The occurrence of superplastic ductilities at strain rates at and above $10^{-2} \mathrm{~s}^{-1}$ provides direct confirmation for high strain rate superplasticity in this material [40]. The true stress-true strain curves are not included in this report but, as anticipated from Fig. 1(a) and (b), they reveal no evidence for a steady-state flow stress even at the highest temperature of $1073 \mathrm{~K}$ and this is consistent with the high temperature properties of the nanostructured CoCrFeNiMn HEA [17].

It was reported earlier that $\mathrm{Ni}$ is the element having the lowest diffusion coefficient in these HEAs [41] and it was suggested that, as in conventional superplasticity where grain boundary diffusion is rate-controlling [42], the rate of flow is controlled by boundary diffusion of the $\mathrm{Ni}$ atoms. Furthermore, the advent of superplastic elongations shows that GBS occurs in this alloy at these high temperatures [43].

An analysis of the tensile curves in Fig. 1(a,b) shows that the flow stress decreases with both increasing temperature and decreasing strain rate. There is excellent evidence for true superplastic flow in the $\mathrm{CoCrFeNiMnTi} i_{0.1}$ alloy because the maximum elongations are within the superplastic range, in Fig. 2 there is no incipient necking within the gauge length and in Figs 4 and 7 the grains are essentially equiaxed after tensile testing. All of these results support the occurrence of true superplastic flow and yet the strain rate sensitivity is $m \approx 0.3$ which is lower than the anticipated value of $\mathrm{m} \approx 0.5$ for superplasticity where flow occurs through grain boundary sliding $[42,43]$. Nevertheless, this result is consistent with the earlier report of a strain rate sensitivity of $\sim 0.31$ in the CoCrFeNiMn HEA under conditions where the elongations were within the superplastic range [17]. As noted earlier, this apparent inconsistency arises because, 
unlike conventional superplastic metals where there is little or no grain growth during tensile testing, there is grain growth in these nanostructured HEAs during tensile testing under superplastic conditions. For example, in the present experiments the grain size immediately after HPT processing was only $\sim 30 \mathrm{~nm}$ but the final grain size after tensile testing at $973 \mathrm{~K}$ was $\sim 500 \mathrm{~nm}$. This corresponds to an increase in grain size by more than an order of magnitude and yet, because of the exceptionally small grain size produced by HPT, the final grain size remains within the superplastic regime. As demonstrated for the CoCrFeNiMn HEA [17], the occurrence of substantial grain growth during testing leads to a displacement in the datum points in a conventional plot of flow stress against strain rate and thereby gives an erroneously low value of $m$.

It is well known that superplasticity requires a grain size smaller than $\sim 10 \mu \mathrm{m}$ and reasonable thermal stability so that superplastic flow is favored in two-phase materials where the presence of separate phases inhibits grain growth at elevated temperatures [20]. In the present experiments, the grain size of $\sim 30 \mathrm{~nm}$ after HPT processing easily fulfills the requirement for superplasticity and the grain size is retained within the superplastic range at high temperatures due to the presence of precipitates and the sluggish diffusion which is an inherent feature of HEAs [41,44]. A microstructural analysis of the samples tested at 973 and $1073 \mathrm{~K}$ confirmed the presence of precipitates within the matrix and some of these precipitates are marked by arrows in Figs 4 and 7. Analyses show that the microstructure consists of a mixture of an $f c c$ phase as the matrix and $b c c$ and $\sigma$ (Cr-rich precipitate) phases where this is consistent with earlier research on the CoCrFeNiMn HEA [17,28]. Close inspection of Fig. 4 shows these precipitates are typically $<1 \mu \mathrm{m}$ in diameter and form along the grain boundaries where it is reasonable to assume that they hinder grain boundary migration and the associated grain growth.

Superplasticity is a diffusion-controlled process requiring a testing temperature at or above $\sim 0.5 T_{m}$, where $T_{m}$ is the absolute melting temperature of the material [20]. In the present 
experiments, the testing temperatures are consistent with this requirement because the CoCrFeNiMn phase diagram gives $T_{\mathrm{m}} \approx 1613 \mathrm{~K}$ [45]. Nevertheless, the results show that microcracks form at the highest testing temperature of $1073 \mathrm{~K}$ and this leads to a deterioration in the measured elongations to failure. .

\subsection{The significance of superplasticity in tensile testing of the CoCrFeNiMnTi $i_{0.1} H E A$.}

Theory shows that GBS accommodated by intragranular glide and the subsequent climb of dislocations into grain boundaries leads to a superplastic strain rate, $\dot{\varepsilon}_{\mathrm{sp}}$, having the following relationship [42]:

$$
\dot{\varepsilon}_{\mathrm{sp}}=\frac{A D_{\mathrm{gb}} G \mathbf{b}}{k T}\left(\frac{\mathbf{b}}{d}\right)^{2}\left(\frac{\sigma}{G}\right)^{2}
$$

where $A$ is a dimensionless constant having a value of $\sim 10, D_{\mathrm{gb}}$ is the coefficient for grain boundary diffusion, $G$ is the shear modulus, $\mathbf{b}$ is the Burgers vector, $k$ is Boltzmann's constant, $T$ is the absolute temperature, $d$ is the grain size and $\sigma$ is the applied stress. The flow mechanism was evaluated for the UFG CoCrFeNiMnTi $i_{0.1}$ HEA by re-arranging Eq. (1), so that the experimental data were plotted in the form of the grain size and temperature compensated strain rate against the normalized stress as demonstrated in Fig. 8. This plot was achieved by taking $D_{\mathrm{gb}}=D_{o} \exp \left(-Q_{\mathrm{gb}} / R T\right)$ where $D_{o}$ is a frequency factor $\left(19.4 \times 10^{-4} \mathrm{~m}^{2} \mathrm{~s}^{-1}\right.$ for pure Ni [50]), $Q_{\mathrm{gb}}$ is the activation energy for grain boundary diffusion $\left(113 \mathrm{~kJ} \mathrm{~mol}^{-1}\right.$ for superplastic deformation of the UFG HEA [17]) and $R$ is the gas constant, $\mathbf{b}=2.55 \times 10^{-10} \mathrm{~m} \mathrm{[50]} \mathrm{and} G=$ $85-\{16 /[\exp (448 / T)-1]\}$ GPa [51]. The plot was constructed taking grain sizes in the range of 0.5-3.0 $\mu \mathrm{m}$ measured in the gauge sections after tensile testing and the solid line labelled $\dot{\varepsilon}_{\text {sp }}$ in Fig. 8 shows the theoretically predicted rate for superplasticity based on Eq. (1).

It is now well established that the relationship for superplasticity given by Eq. (1) provides an excellent description not only for the superplastic flow of conventional metals with grain sizes of a few micrometers but also for bulk ultrafine-grained materials having submicrometer grain sizes produced by severe plastic deformation [46-49]. Specifically, detailed calculations 
show very good agreement between published data and the predictions of Eq. (1) for both aluminum-based and magnesium-based UFG alloys [49]. It is now readily apparent from Fig. 8 that the experimental data for the CoCrFeNiMnTi ${ }_{0.1}$ HEA are also in excellent agreement with the theoretical prediction for flow controlled by GBS. Thus, there is a general agreement and consistency between the superplastic behavior occurring in the present HEA and in other nanostructured materials subjected to SPD processing as well as in conventional superplastic alloys.

\subsection{An examination of the effect of Ti on superplasticity in the CoCrFeNiMn HEA}

In order to determine the effect of the addition of a minor amount of Ti on superplasticity in the CoCrFeNiMn HEA, Table 1 summarizes the results available for the elongations to failure after processing by HPT [17] and rolling [19]. Since superplasticity requires an elongation of at least $400 \%$, the results from rolling give elongations of up to $320 \%$ and this is not within the true superplastic range. Nevertheless, these results are included because the data were interpreted as indicative of a superplastic-like flow but the overall elongations were limited by the development of cavitation. The HPT-processed CoCrFeNiMn samples tested at $973 \mathrm{~K}$ and the HPT-processed CoCrFeNiMnTi ${ }_{0.1}$ samples tested at 873-1073 K both exhibit high strain rate superplasticity. The important conclusion from this comparison is that the elongations to failure are significantly enhanced in the CoCrFeNiMn HEA under all testing conditions through the addition of only a very small amount ( 2 at.\%) of Ti.

To understand the effect of adding a small amount of Ti to the CoCrFeNiMn HEA, Table 2 summarizes the results reported for the grain sizes and the volume fractions of precipitates in CoCrFeNiMn and $\mathrm{CoCrFeNiMnTi}_{0.1}$ HEAs where the values of these two quantities were estimated from SEM observations and XRD data, respectively. Inspection of Table 2 shows there are smaller grain sizes and higher volume fractions of precipitates in the CoCrFeNiMnTi $i_{0.1}$ HEA and both of these changes will effectively enhance the occurrence of superplasticity. The greater stability of precipitates in acting as effective obstacles to grain 
growth in the CoCrFeNiMnTi ${ }_{0.1}$ HEA is due to the solid solution effect of the Ti atoms which decreases the diffusion rate. In practice, the larger numbers of compositional elements produce increased potential energy fluctuations between the atomic lattice sites and this leads to an increase in the diffusive activation energy and thereby produces more sluggish diffusion [41]. It is important to note also that the atomic radius of $\mathrm{Ti}(176 \mathrm{pm})$ is significantly larger than the average atomic radii for the other elements $(\sim 155 \mathrm{pm})$ and this will also affect the diffusion rate in this Ti-doped HEA. Therefore, it is concluded that the superplastic properties of the CoCrFeNiMn HEA are significantly improved through the addition of only a relatively minor amount of titanium and it is probable that similar minor additions of other elements may also have beneficial effects in other HEAs.

\section{Summary and conclusions}

1. An addition of 2 at. $\% \mathrm{Ti}$ to a CoCrFeNiMn HEA produced exceptional grain refinement to a grain size of $\sim 30 \mathrm{~nm}$ when processing by HPT at RT. Subsequent tensile testing gave superplastic elongations at temperatures from 873 to $1073 \mathrm{~K}$ with a maximum elongation of $830 \%$ at $973 \mathrm{~K}$ using an initial strain rate of $1.0 \times 10^{-2} \mathrm{~s}^{-1}$.

2. The advent of true superplasticity was confirmed by the retention of an equiaxed grain structure after tensile testing and the absence of any visible necking within the gauge length. It is shown by calculation that flow occurs by the conventional mechanism for superplasticity. The measured strain rate sensitivity of $m \approx 0.3$ is lower than anticipated but this low value is directly attributed to the occurrence of grain growth during the tensile testing.

3. The presence of a Ti addition of only 2 at.\% leads to a significantly smaller grain size and a larger volume fraction of precipitates than in the CoCrFeNiMn HEA without a Ti addition. Both of these effects contribute to improved superplastic properties thereby demonstrating the potential for significantly improving the properties of other HEAs through the addition of only minor amounts of other elements. 


\section{Acknowledgements}

This work was supported by the National Elites Foundation of Islamic Republic of Iran and in part by the European Research Council under Grant Agreement No. 267464-SPDMETALS (TGL). 


\section{References}

1. C.J. Tong, Y.L. Chen, S.K. Chen, J.W. Yeh, T.T Shun, C.H. Tsau, S.J. Lin, S.Y. Chang, Microstructure characterization of $\mathrm{Al}_{\mathrm{x}} \mathrm{CoCrCuFeNi}$ high-entropy alloy system with multiprincipal elements, Metall. Mater. Trans. A 36A (2005) 881-893.

2. J.W. Yeh, S.K. Chen, S.J. Lin, J.Y. Gan, T.S. Chin, T.T. Shun, C.H. Tsau, S.Y. Chang, Nanostructured high-entropy alloys with multiple principal elements: novel alloy design concepts and outcomes, Adv. Eng. Mater. 6 (2004) 299-303.

3. J.W. Yeh, S.K. Chen, S.J. Lin, J.Y. Gan, T.S. Chin, T.T. Shun, C.H. Tsau, S.Y. Chang, Nanostructured high-entropy alloys with multiple principal elements: Novel alloy design concepts and outcomes, Adv. Eng. Mater. 6 (2004) 299-303.

4. F. Otto, A. Dlouhý, Ch. Somsen, H. Bei, G. Eggeler, E.P. George, The influences of temperature and microstructure on the tensile properties of a $\mathrm{CoCrFeMnNi}$ high-entropy alloy, Acta Mater. 61 (2013) 5743-5755.

5. B. Cantor, I.T.H. Chang, P. Knight, A.J.B. Vincent, Microstructural development in equiatomic multicomponent alloys, Mater. Sci. Eng. A 375-377 (2004) 213-218.

6. F. Otto, Y. Yang, H. Bei, E.P. George, Relative effects of enthalpy and entropy on the phase stability of equiatomic high-entropy alloys, Acta Mater. 61 (2013) 2628-2638.

7. Y. Wu, W.H. Liu, X.L. Wang, D. Ma, A.D. Stoica, T.G. Nieh, Z.B. He, Z.P. Lu, In-situ neutron diffraction study of deformation behavior of a multi-component high-entropy alloy, Appl. Phys. Lett. 104 (2014) 051910.

8. M.H. Tsai, J.W. Yeh, High-entropy alloys: A critical review, Mater. Res. Lett. 2 ( 2014) 107-123.

9. A. Gali, E.P. George, Tensile properties of high- and medium-entropy alloys, Intermetallics 39 (2013) 74-78.

10. J.Y. He, C. Zhu, D.Q. Zhou, W.H. Liu, T.G. Nieh, Z.P. Lu, Steady state flow of the FeCoNiCrMn high entropy alloy at elevated temperatures, Intermetallics 55 (2014) 9-14. 
11. Z. Wu, H. Bei, G.M. Pharr, E.P. George, Temperature dependence of the mechanical properties of equiatomic solid solution alloys with face-centered cubic crystal structures, Acta Mater. 81 (2014) 428-441.

12. N.D. Stepanov, D.G. Shaysultanov, N.Yu. Yurchenko, S.V. Zherebtsov, A.N. Ladygin, G.A. Salishchev, M.A. Tikhonovsky, High temperature deformation behavior and dynamic recrystallization in CoCrFeNiMn high entropy alloy, Mater.Sci.Eng. A 636 (2015) 188195.

13. A.V. Kuznetsov, D.G. Shaysultanov, N.D. Stepanov, G.A. Salishchev, O.N. Senkov, Tensile properties of an $\mathrm{AlCrCuNiFeCo}$ high-entropy alloy in as-cast and wrought conditions, Mater. Sci. Eng. A533 (2012) 107-118.

14. A.V. Kuznetsov, D.G. Shaysultanov, N.D. Stepanov, G.A. Salishchev, O.N. Senkov, Superplasticity of AlCoCrCuFeNi high entropy alloy, Mater. Sci. Forum 735 (2013) 146151.

15. D.G. Shaysultanov, N.D. Stepanov, A.V. Kuznetsov, G.A. Salishchev, O.N. Senkov, Phase composition and superplastic behavior of a wrought AlCoCrCuFeNi high-entropy alloy, JOM 65 (2013) 1815-1828.

16. N.D. Stepanov, D.G. Shaysultanov. G.A. Salishchev, O.N. Senkov, Mechanical behavior and microstructure evolution during superplastic deformation of the fine-grained AlCoCrCuFeNi high entropy alloy, Mater. Sci. Forum 838-839 (2016) 302-307.

17. H. Shahmir, J. He, Z. Lu, M. Kawasaki, T.G. Langdon, Evidence for superplasticity in a CoCrFeNiMn high-entropy alloy processed by high-pressure torsion, Mater. Sci. Eng. A 685 (2017) 342-348.

18. H. Shahmir, M. Kawasaki, T.G. Langdon, The potential for achieving superplasticity in high-entropy alloys processed by severe plastic deformation, IOP Conf. Series: Mater. Sci. Eng. 194 (2017) 012040 (1-6). 
19. S.R. Reddy, S. Bapari, P.P. Bhattacharjee, A.H. Chokshi, Superplastic-like flow in a finegrained equiatomic CoCrFeMnNi high-entropy alloy, Mater. Res. Lett. 5 (2017) 408-414.

20. T.G. Langdon, The mechanical properties of superplastic materials, Metall. Trans. A 13A (1982) 689-701.

21. R.Z. Valiev, R.K.Islamgaliev, I.V. Alexandrov, Bulk nanostructured materials from severe plastic deformation, Prog. Mater. Sci. 45 (2000) 103-189.

22. T.G. Langdon, Twenty-five years of ultrafine-grained materials: Achieving exceptional properties through grain refinement, Acta Mater. 61 (2013) 7035-7059.

23. A.P. Zhilyaev, T.G. Langdon, Using high-pressure torsion for metal processing: Fundamentals and applications, Prog. Mater. Sci. 53 (2008) 893-979.

24. A.P. Zhilyaev, B.K. Kim, G.V. Nurislamova, M.D. Baró, J.A. Szpunar, T.G. Langdon, Orientation imaging microscopy of ultrafine-grained nickel, Scr. Mater. 46 (2002) 575580.

25. A.P. Zhilyaev, G.V. Nurislamova, B.K. Kim, M.D. Baró, J.A. Szpunar, T.G. Langdon, Experimental parameters influencing grain refinement and microstructural evolution during high-pressure torsion, Acta Mater. 51 (2003) 753-765.

26. J. Wongsa-Ngam, M. Kawasaki, T.G. Langdon, A comparison of microstructures and mechanical properties in a $\mathrm{Cu}-\mathrm{Zr}$ alloy processed using different SPD techniques, J. Mater. Sci. 48 (2013) 4653-4660.

27. T.G. Langdon, Seventy-five years of superplasticity: Historic developments and new opportunities, J. Mater. Sci. 44 (2009) 5998-6010.

28. H. Shahmir, J.Y. He, Z.P. Lu, M. Kawasaki, T.G. Langdon, Effect of annealing on mechanical properties of a nanocrystalline $\mathrm{CoCrFeNiMn} \mathrm{high-entropy} \mathrm{alloy} \mathrm{processed} \mathrm{by}$ high-pressure torsion, Mater. Sci. Eng. A676 (2016) 294. 
29. R.B. Figueiredo, P.R. Cetlin, T.G. Langdon, Using finite element modeling to examine the flow processes in quasi-constrained high-pressure torsion, Mater. Sci. Eng. A528 (2011) 8198-8204.

30. A. Loucif, R.B. Figueiredo, M. Kawasaki, T. Baudin, F. Brisset, R. Chemam, T.G. Langdon, Effect of aging on microstructural development in an Al-Mg-Si alloy processed by high-pressure torsion, J. Mater. Sci. 47 (2012) 7815-7820.

31. H. Ishikawa, F.A. Mohamed, T.G. Langdon, The influence of strain rate on ductility in the superplastic Zn-22\% Al eutectoid, Phil. Mag. 32 (1975) 1269-1271.

32. T.G. Langdon, Fracture processes in superplastic flow, Metal Sci. 16 (1982) 175-183.

33. G.K. Williamson, W.H. Hall, X-ray line broadening from filed aluminium and wolfram, Acta Metall. 1 (1953) 22-31.

34. G.K. Williamson, R.E. Smallman, Dislocation densities in some annealed and cold-worked metals from measurements on the X-ray debye-scherrer spectrum, Phil. Mag. 1 (1956) 3445.

35. Z. Zhang, F. Zhou, E. J. Lavernia, On the analysis of grain size in bulk nanocrystalline materials via X-ray, Metall. Mater. Trans. A, 34A (2003) 1349-1355.

36. B. Schuh, F. Mendez-Martin, B. Völker, E.P. George, H. Clemens, R. Pippan, A. Hohenwarter, Mechanical properties, microstructure and thermal stability of a nanocrystalline $\mathrm{CoCrFeMnNi}$ high-entropy alloy after severe plastic deformation, Acta Mater. 96 (2015) 258-268

37. E.J. Pickering, R. Muñoz-Moreno, H.J. Stone, N.G. Jones, Precipitation in the equiatomic high-entropy alloy CrMnFeCoNi, Scr. Mater. 113 (2016) 106-109.

38. M.H. Tsai, H. Yuan, G. Cheng, W. Xu, W.W. Jian, M.H. Chuang, C.C. Juan, A.C. Yeh, S.J. Lin, Y. Zhu, Significant hardening due to the formation of a sigma phase matrix in a high entropy alloy, Intermetallics 33 (2013) 81-86. 
39. F. Zhang, C. Zhang, S.L. Chen, J. Zhu, W.S. Cao, U.R. Kattner, An understanding of high entropy alloys from phase diagram calculations, CALPHAD 45(2014)1-10.

40. K. Higashi, M. Mabuchi, T.G. Langdon, High-strain-rate superplasticity in metallic materials and the potential for ceramic materials, ISIJ Intl. 36 (1996) 1423-1438.

41. K.Y. Tsai, M.H. Tsai, J.W. Yeh, Sluggish diffusion in $\mathrm{Co}-\mathrm{Cr}-\mathrm{Fe}-\mathrm{Mn}-\mathrm{Ni}$ high-entropy alloys, Acta Mater. 61 (2013) 4887-4897.

42. T.G. Langdon, A unified approach to grain boundary sliding in creep and superplasticity, Acta Metall. Mater. 42 (1994) 2437-2443.

43. T.G. Langdon, An evaluation of the strain contributed by grain boundary sliding in superplasticity, Mater. Sci. Eng. A174 (1994) 225-230.

44. S.Y. Chang, C.E. Li, Y.C. Huang, H.F. Hsu, J.W. Yeh, S.J. Lin, Structural and thermodynamic factors of suppressed interdiffusion kinetics in multi-component highentropy materials, Sci. Reports 4 (2014) 4162.

45. M. Laurent-Brocq, A. Akhatova, L. Perrière, S. Chebini, X. Sauvage, E. Leroy, Y. Champion, Insights into the phase diagram of the CrMnFeCoNi high entropy alloy, Acta Mater. 88 (2015) 355-365.

46. M. Kawasaki, T.G. Langdon, Principles of superplasticity in ultrafine-grained materials, J. Mater. Sc i. 42 (2007) 1782-1796.

47. M. Kawasaki, N. Balasubramanian, T.G. Langdon, Flow mechanisms in ultrafine-grained metals with an emphasis on superplasticity, Mater. Sci. Eng. A 528 (2011) 6624-6629.

48. M. Kawasaki, T.G. Langdon, Review: achieving superplasticity in metals processed by high-pressure torsion, J. Mater. Sci. 49 (2014) 6487-6496.

49. M. Kawasaki, T.G. Langdon, Review: achieving superplastic properties in ultrafinegrained materials at high temperatures, J. Mater. Sci. 51 (2016) 19-32.

50. J.Y. He, C. Zhu, D.Q. Zhou, W.H. Liu, T.G. Nieh, Z.P. Lu, Steady state flow of the FeCoNiCrMn high entropy alloy at elevated temperatures, Intermetallics 55 (2014) 9-14. 
51. G. Laplanche, P. Gadaud, O. Horst, F. Otto, G. Eggeler, E.P. George, Temperature dependencies of the elastic moduli and thermal expansion coefficient of an equiatomic, single-phase CoCrFeMnNi high-entropy alloy, J. Alloys. Compds 623 (2015) 348-353. 


\section{Tables captions:}

Table 1 Experimental parameters and elongations to failure in investigations of CoCrFeNiMn HEAs [17,19].

Table 2. Comparison of grain sizes and volume fractions of precipitates in CoCrFeNiMn $[17,28]$ and $\mathrm{CoCrFeNiMnTi} i_{0.1}$ HEAs.

\section{Figures captions:}

Fig. 1 (a) Engineering stress versus engineering strain for samples processed by HPT through 5 turns at an initial strain rate of $1.0 \times 10^{-2} \mathrm{~s}^{-1}$ and different temperatures, (b) engineering stress versus engineering strain for samples processed at $973 \mathrm{~K}$ at different initial strain rates and (c) flow stress versus initial strain rate at $973 \mathrm{~K}$ to determine the strain rate sensitivity, $m$.

Fig. 2 Examples of superplasticity in a CoCrFeNiMnTi ${ }_{0.1}$ HEA after processing by HPT and testing in tension at $973 \mathrm{~K}$ : the upper sample is undeformed.

Fig. 3 X-ray patterns of CoCrFeNiMnT 0.1 HEA before (homogenized) and after HPT processing and in the grip sections after tensile testing at 973 and $1073 \mathrm{~K}$ with an initial strain rate of $1.0 \times 10^{-2} \mathrm{~s}^{-1}$.

Fig. 4 SEM micrographs of sample after tensile testing at $973 \mathrm{~K}$ with initial strain rates of (a-c) $1.0 \times 10^{-2} \mathrm{~s}^{-1}$ and (d-f) $1.0 \times 10^{-3} \mathrm{~s}^{-1}$ corresponding to elongations of $\sim 830 \%$ and $\sim 650 \%$, respectively, with the tensile direction (TD) lying horizontal as indicated; arrows denote precipitates and circles show grains containing twins, with micro-cracking visible at the interfaces between the matrix and precipitates in (a).

Fig. 5 X-ray patterns in the grip sections after HPT processing and after tensile testing at $973 \mathrm{~K}$ with initial strain rates from $1.0 \times 10^{-3}$ to $1.0 \times 10^{-1} \mathrm{~s}^{-1}$.

Fig. 6 Upper curve shows Vickers microhardness in the grip sections before ( 0 min) and after tensile testing at $973 \mathrm{~K}$ with initial strain rates from $1.0 \times 10^{-3}$ to $1.0 \times 10^{-1} \mathrm{~s}^{-1}$ taking $20-140$ min (corresponding to holding time to reach $973 \mathrm{~K}$ plus testing time); the lower dashed line at $\mathrm{Hv} \approx 140$ denotes the initial hardness in the homogenized condition. 
Fig. 7 SEM micrographs at (a,b) the head at different magnifications, (c) near the head and (d) in the grip section of a sample after tensile testing at $1073 \mathrm{~K}$ with an initial strain rate of $1.0 \times$ $10^{-2} \mathrm{~s}^{-1}$ corresponding to an elongation of $\sim 570 \%$; the tensile direction (TD) is indicated, EDS analyses are recorded for the points labeled A-B and C-D in (a) and (d), respectively, where points $\mathrm{A}$ and $\mathrm{C}$ correspond to the matrix and points $\mathrm{B}$ and $\mathrm{D}$ show the chemical compositions of the oxides formed in microcracks and at precipitates during tensile testing.

Fig. 8 Temperature and grain size compensated strain rate versus normalized stress showing good agreement with the theoretical prediction for conventional superplasticity, $\dot{\varepsilon}_{\text {sp }}$. 

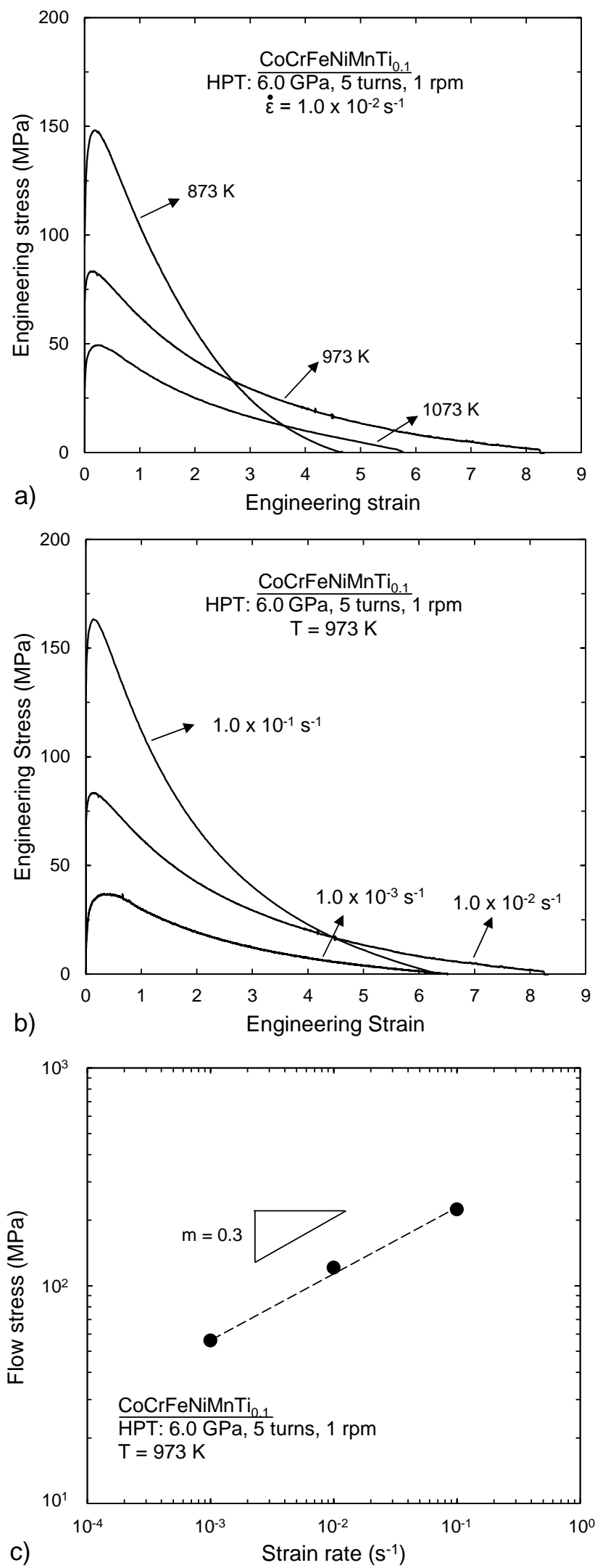

Fig. 1 (a) Engineering stress versus engineering strain for samples processed by HPT through 5 turns at an initial strain rate of $1.0 \times 10^{-2} \mathrm{~s}^{-1}$ and different temperatures, (b) engineering stress versus engineering strain for samples processed at $973 \mathrm{~K}$ at different initial strain rates and (c) flow stress versus initial strain rate at $973 \mathrm{~K}$ to determine the strain rate sensitivity, $m$. 


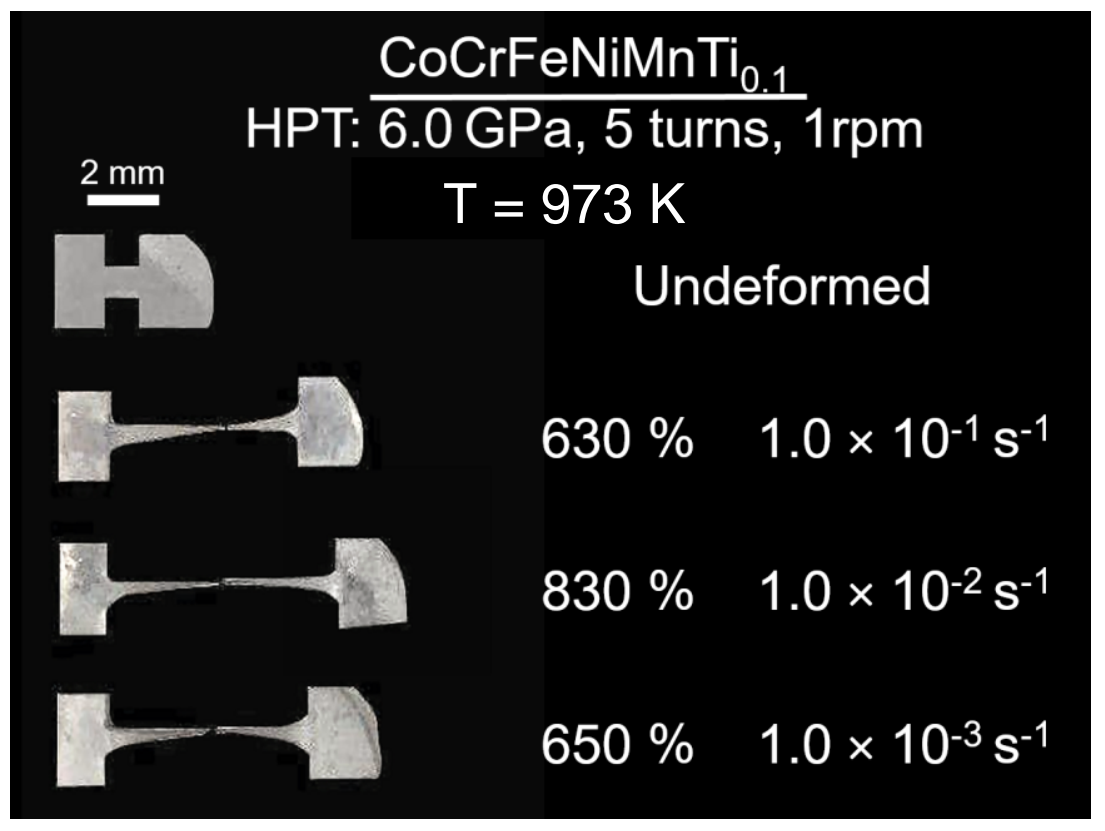

Fig. 2 Examples of superplasticity in a $\mathrm{CoCrFeNiMnTi} \mathrm{i}_{0.1}$ HEA after processing by HPT and testing in tension at at $973 \mathrm{~K}$ : the upper sample is undeformed. 


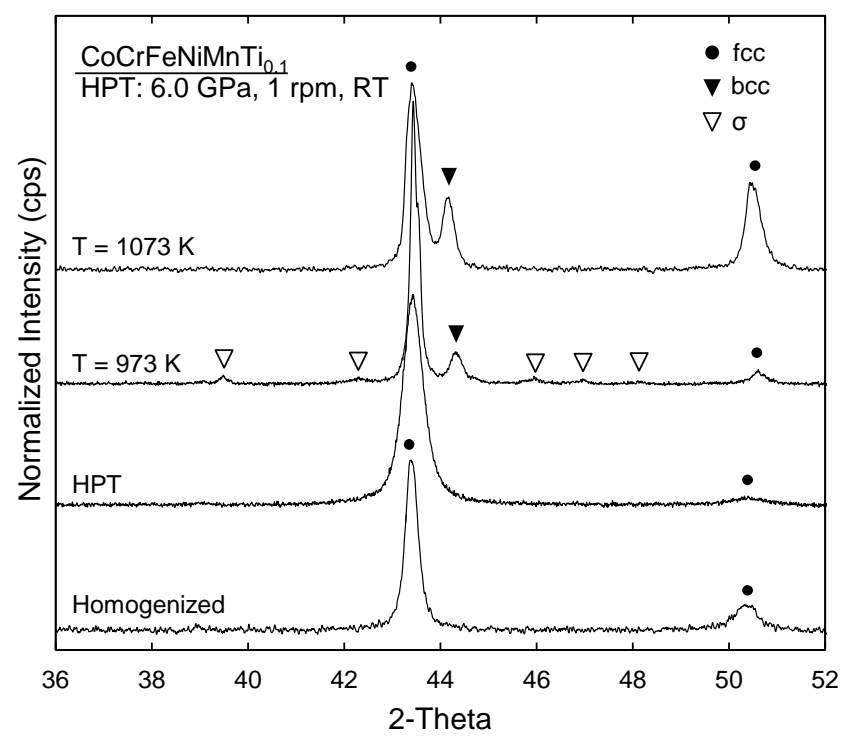

Fig. 3 X-ray patterns of $\mathrm{CoCrFeNiMnT}_{0.1}$ HEA before (homogenized) and after HPT processing and in the grip sections after tensile testing at 973 and $1073 \mathrm{~K}$ with an initial strain rate of $1.0 \times 10^{-2} \mathrm{~s}^{-1}$. 


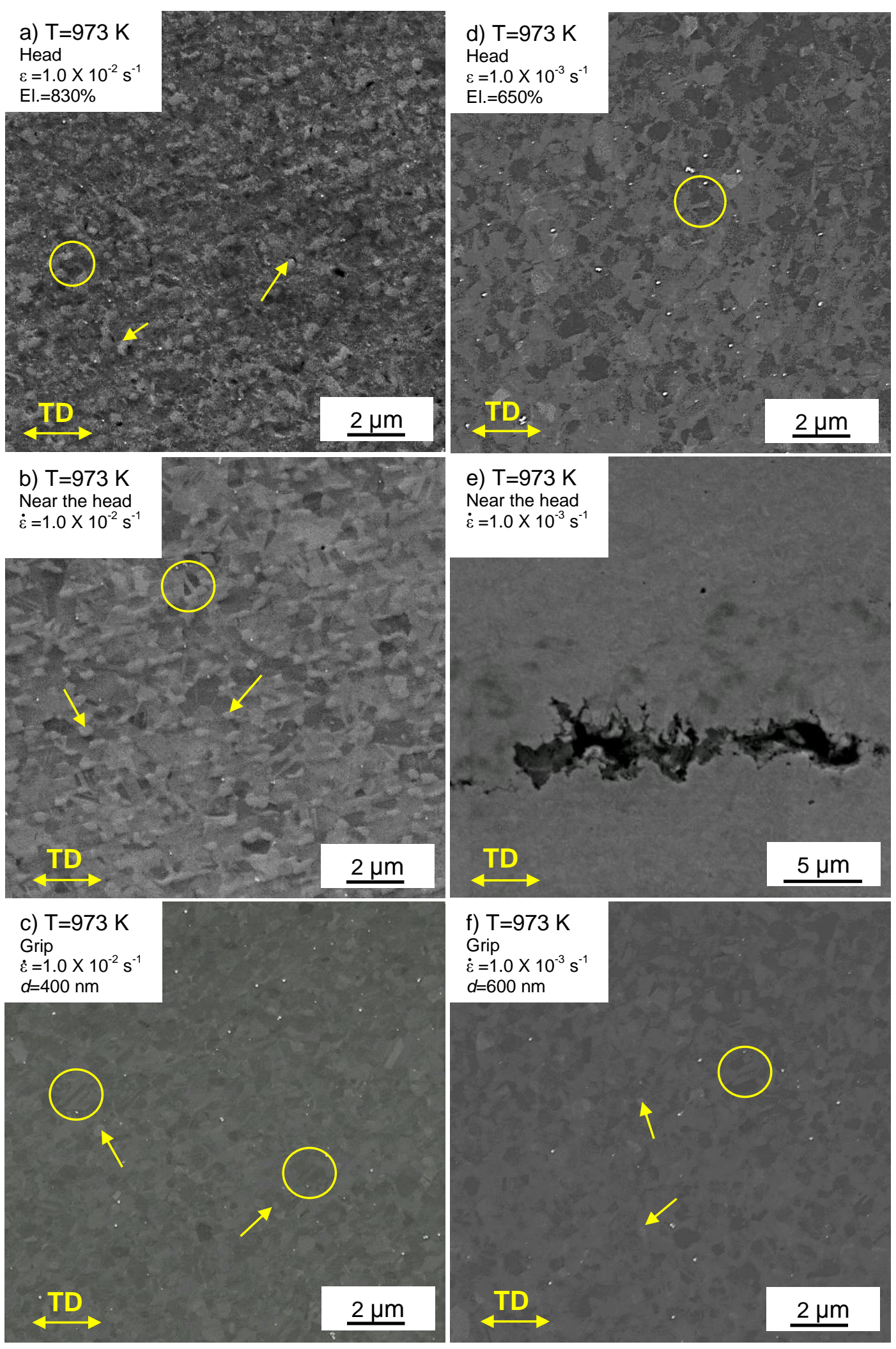

Fig. 4 SEM micrographs of sample after tensile testing at $973 \mathrm{~K}$ with initial strain rate of (a-c) $1.0 \times 10^{-2} \mathrm{~s}^{-1}$ and (d-f) $1.0 \times 10^{-3} \mathrm{~s}^{-1}$ corresponding to elongation of $\sim 830 \%$ and $\sim 650 \%$, respectively, with the tensile direction (TD) lying horizontal as indicated; arrows denote precipitates and circles show grains containing twins, with micro-cracking visible at the interfaces between the matrix and precipitates in (a). 


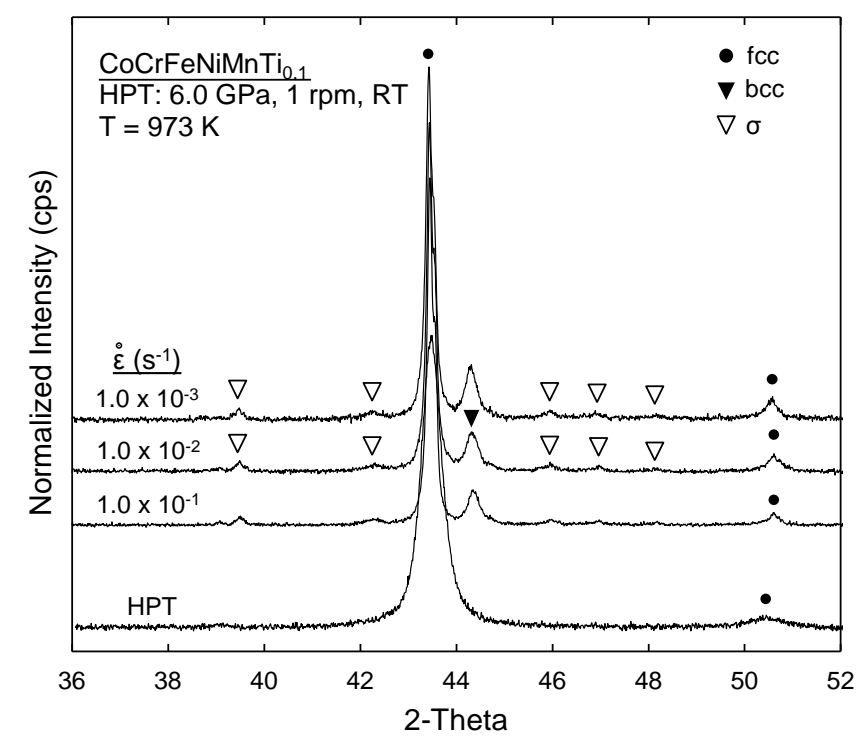

Fig. 5 X-ray patterns in the grip sections after HPT processing and after tensile testing at $973 \mathrm{~K}$ with initial strain rate from $1.0 \times 10^{-3}$ to $1.0 \times 10^{-1} \mathrm{~s}^{-1}$.

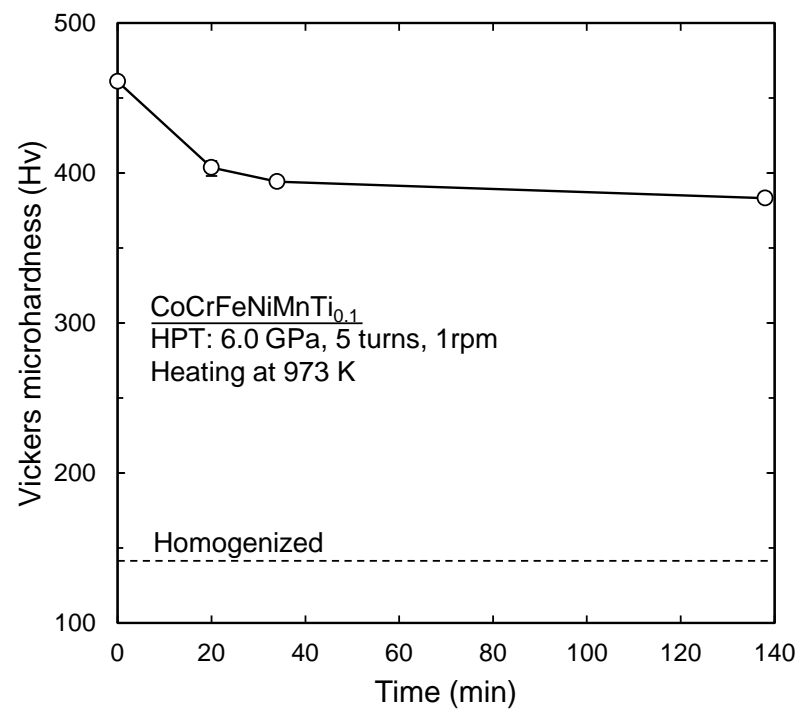

Fig. 6 Upper curve shows Vickers microhardness in the grip sections before ( 0 min) and after tensile testing at $973 \mathrm{~K}$ with initial strain rates from $1.0 \times 10^{-3}$ to $1.0 \times 10^{-1} \mathrm{~s}^{-1}$ taking $20-140$ min (corresponding to holding time to reach $973 \mathrm{~K}$ plus testing time); the lower dashed line at $\mathrm{Hv} \approx 140$ denotes the initial hardness in the homogenized condition. 


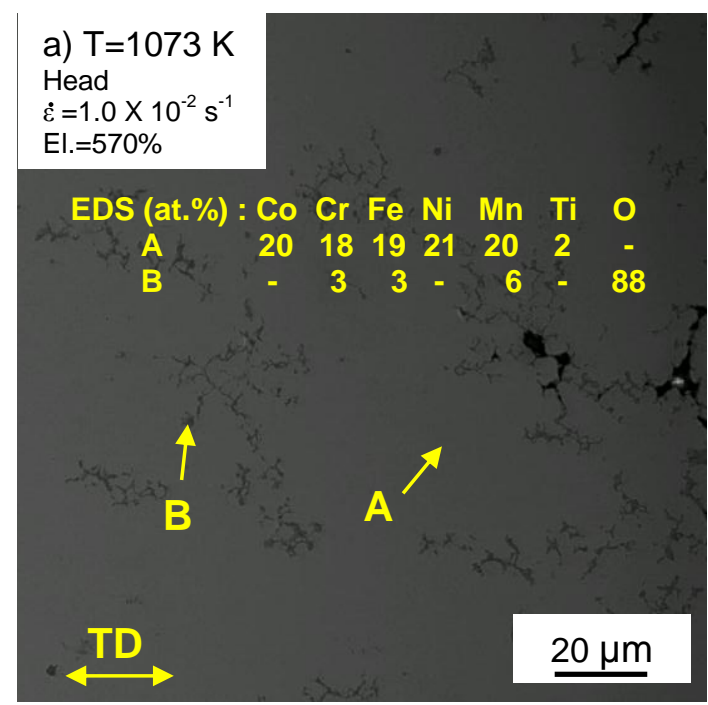

$$
\begin{aligned}
& \text { b) } T=1073 \mathrm{~K} \\
& \text { Head } \\
& \dot{\varepsilon}=1.0 \times 10^{-2} \mathrm{~s}^{-1} \\
& \text { El. }=570 \%
\end{aligned}
$$

\section{c) $\mathrm{T}=1073 \mathrm{~K}$ Near the head $\dot{\varepsilon}=1.0 \times 10^{-2} \mathrm{~s}^{-1}$ $d=3 \mu \mathrm{m}$}

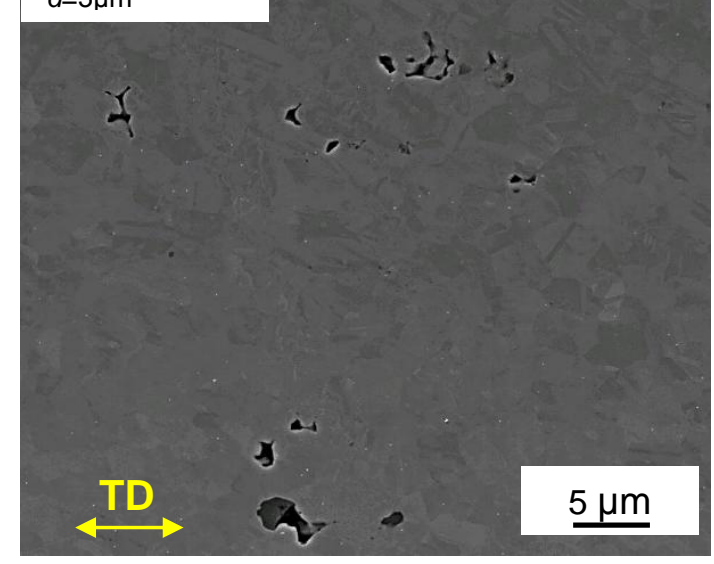

Fig. 7 SEM micrographs at (a,b) the head at different magnifications, (c) near the head and (d) in the grip section of a sample after tensile testing at $1073 \mathrm{~K}$ with an initial strain rate of $1.0 \times 10^{-2} \mathrm{~s}^{-1}$ corresponding to an elongation of $\sim 570 \%$; the tensile direction (TD) is indicated, EDS analyses are recorded for the points labeled A-B and C-D in (a) and (d), respectively, where points $A$ and $C$ correspond to the matrix and points $B$ and $D$ show the chemical compositions of the oxides formed in microcracks and at precipitates during tensile testing. 


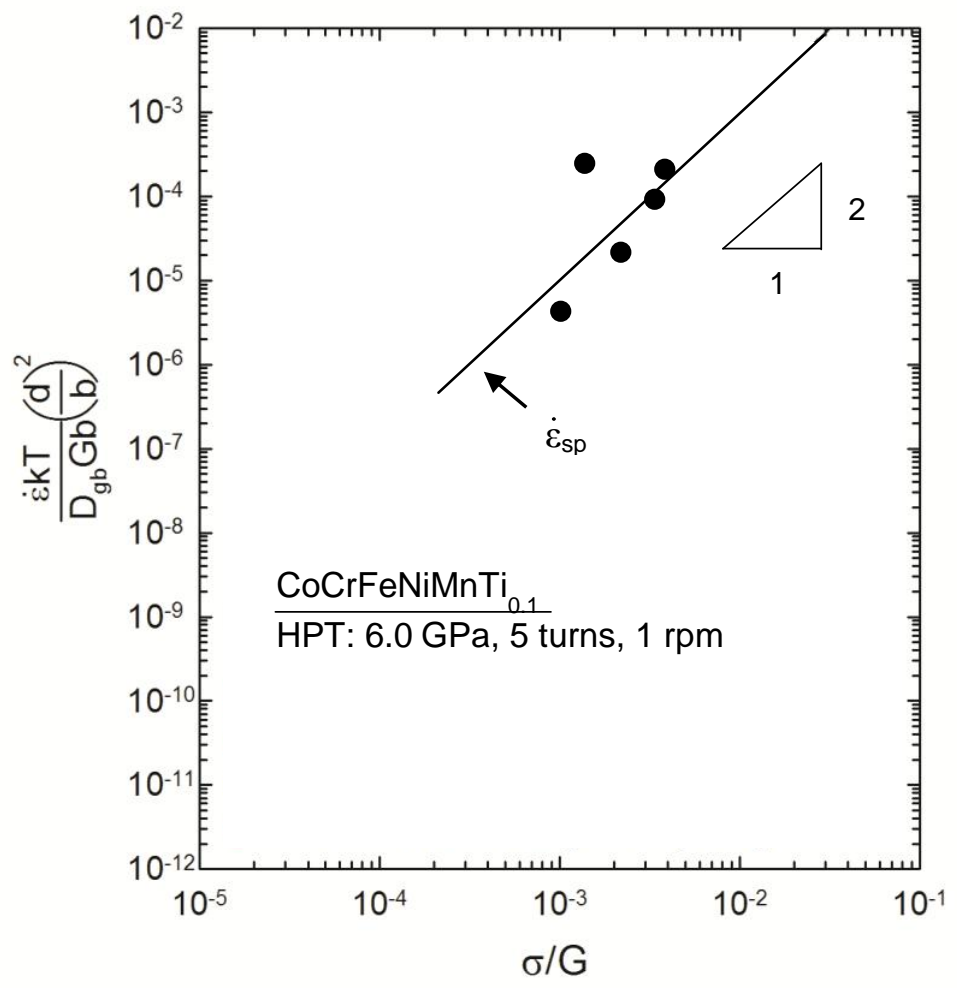

Fig. 8 Temperature and grain size compensated strain rate versus normalized stress showing good agreement with the theoretical prediction for conventional superplasticity, $\dot{\varepsilon}_{\mathrm{sp}}$. 
Table 1 Experimental parameters and elongations to failure in investigations of CoCrFeNiMn HEAs [17,19].

\begin{tabular}{|c|c|c|c|c|c|c|}
\hline Composition & Processing & $\begin{array}{c}\text { Gauge } \\
\text { dimensions } \\
\left(\mathrm{mm}^{3}\right)\end{array}$ & $\begin{array}{l}\text { Temperature } \\
\text { (K) }\end{array}$ & $\begin{array}{l}\text { Strain } \\
\text { rate }\left(\mathrm{s}^{-1}\right)\end{array}$ & $\begin{array}{c}\text { Elongation } \\
(\%)\end{array}$ & Ref. \\
\hline \multirow[t]{10}{*}{ CoCrFeNiMn } & HPT & $1.1 \times 1.0 \times 0.6$ & 773 & $1.0 \times 10^{-3}$ & 160 & Shahmir et \\
\hline & & & 873 & $1.0 \times 10^{-1}$ & 330 & al. [17] \\
\hline & & & 873 & $1.0 \times 10^{-2}$ & 400 & \\
\hline & & & 873 & $1.0 \times 10^{-3}$ & 520 & \\
\hline & & & 973 & $1.0 \times 10^{-1}$ & 410 & \\
\hline & & & 973 & $1.0 \times 10^{-2}$ & 500 & \\
\hline & & & 973 & $1.0 \times 10^{-3}$ & 570 & \\
\hline & & & 1073 & $1.0 \times 10^{-1}$ & 310 & \\
\hline & & & 1073 & $1.0 \times 10^{-2}$ & 360 & \\
\hline & & & 1073 & $1.0 \times 10^{-3}$ & 390 & \\
\hline \multirow[t]{3}{*}{ CoCrFeNiMn } & Rolling & $3 \times 1 \times 0.3$ & 1023 & $1.0 \times 10^{-1}$ & 160 & Reddy et al. \\
\hline & & & 1023 & $1.0 \times 10^{-3}$ & 290 & [19] \\
\hline & & & 1023 & $1.0 \times 10^{-4}$ & 320 & \\
\hline \multirow[t]{5}{*}{$\mathrm{CoCrFeNiMnTi}_{0.1}$} & HPT & $1.1 \times 1.0 \times 0.6$ & 873 & $1.0 \times 10^{-2}$ & 460 & This \\
\hline & & & 973 & $1.0 \times 10^{-1}$ & 630 & research \\
\hline & & & 973 & $1.0 \times 10^{-2}$ & 830 & \\
\hline & & & 973 & $1.0 \times 10^{-3}$ & 650 & \\
\hline & & & 1073 & $1.0 \times 10^{-2}$ & 570 & \\
\hline
\end{tabular}


Table 2 Comparison of grain sizes and volume fractions of precipitates in CoCrFeNiMn $[17,28]$ and $\mathrm{CoCrFeNiMnTi} \mathrm{in}_{0.1}$ HEAs.

\begin{tabular}{ccccccc}
\hline Composition & $\begin{array}{c}\text { Temperature } \\
(\mathrm{K})\end{array}$ & $\begin{array}{c}\text { Strain rate } \\
\left(\mathrm{s}^{-1}\right)\end{array}$ & $\begin{array}{c}\text { Elongation } \\
(\%)\end{array}$ & $\begin{array}{c}\mathrm{d}^{\mathrm{a}} \\
(\mu \mathrm{m})\end{array}$ & $\begin{array}{c}\text { Precipitates } \\
(\%)\end{array}$ & Ref. \\
\hline \multirow{2}{*}{ CoCrFeNiMn } & 973 & $1.0 \times 10^{-3}$ & 570 & 1.0 & $7^{\mathrm{b}}$ & Shahmir et al. \\
& 1073 & $1.0 \times 10^{-3}$ & 390 & 5.5 & $5^{\mathrm{b}}$ & {$[17]$} \\
\hline \multirow{3}{*}{ CoCrFeNiMnTi } & 973 & $1.0 \times 10^{-2}$ & 830 & 0.4 & 10 & \\
& 973 & $1.0 \times 10^{-3}$ & 650 & 0.6 & 12 & This research \\
\hline
\end{tabular}

${ }^{\mathrm{a}}$ Grain size in gauge area after testing

${ }^{\mathrm{b}}$ From [28] 